\title{
Differential Effect of Caffeine Administration on Calcium and Vitamin D Metabolism in Young and Adult Rats
}

\author{
JAMES K. YEH and JOHN F. ALOIA
}

\begin{abstract}
Since coffee drinking may lead to a worsening of calcium balance in humans, we studied the serial changes of serum calcium, PTH, 1,25-dihydroxyvitamin D $\left(1,25(\mathrm{OH})_{2} \mathrm{D}\right)$ and calcium balance in young and adult rats after daily administration of caffeine for 4 weeks.

In the young rats, there was an increase in urinary calcium and endogenous fecal calcium excretion after four days of caffeine administration that persisted for the duration of the experiment. Serum calcium decreased on the fourth day of caffeine administration and then returned to control levels. In contrast, the serum PTH and 1,25(OH) $)_{2}$ D remained unchanged initially, but increased after 2 weeks of caffeine administration. The intestinal absorption coefficient of calcium remained unchanged, instead of declining gradually as observed in the young control group. This finding suggests that the intestinal absorption of calcium was stimulated by the increase in $1,25(\mathrm{OH})_{2} \mathrm{D}$ production after chronic administration of caffeine.

In the adult rat group, an increase in the urinary calcium and endogenous fecal calcium excretion and serum levels of PTH was found after caffeine administration. However, the serum $1,25(\mathrm{OH})_{2} \mathrm{D}$ levels and intestinal absorption coefficient of calcium remained the same as in the adult control group. A decrease in the net balance of calcium occurred as a result of increased calcium excretion.

The current study, using an animal model, supports the suggestion that chronic administration of caffeine could lead to negative calcium balance when there is an impaired ability to increase the efficiency of calcium absorption. Such a situation exists in elderly human subjects, since they have a reduced capacity to synthesize $1,25(\mathrm{OH})_{2} \mathrm{D}$.
\end{abstract}

\section{INTRODUCTION}

$\mathrm{N}$ Egative Calcium balance has been associated with caffeine intake in perimenopausal women. (1) A higher caffeine intake has been found in osteoporotic patients as compared to age-matched controls. ${ }^{(2)}$ These observations suggest the possibility that caffeine intake may lead to a deterioration of calcium balance and may contribute to the development of osteoporosis.

Recently, our laboratory observed that urinary excretion and intestinal endogenous excretion of calcium increases in young rats after chronic administration of caffeine. ${ }^{(3)}$ This result is consistent with similar findings in human studies. (1) However, the chronic administration of caffeine to young rats resulted in an increase in intestinal calcium absorption, which compensated for the urinary loss of calcium. As a result, the calcium balance of the young rats did not decrease following caffeine administration. The current study was stimulated by the possibility that the findings in the animal studies differed from those in the human studies as a result of an age-related inability in older humans to increase calcium absorption.

Calcium absorption is regulated by a negative feedback control system. The parathyroid glands serve as a calciumsensing organ which, by secretion of parathyroid hormone (PTH), stimulates the activity of the enzyme 25-hydroxyD-1 $\alpha$-hydroxylase in the kidney. ${ }^{(4)}$ Renal 1,25 -dihydroxyvitamin $\mathrm{D}\left(1,25(\mathrm{OH})_{2} \mathrm{D}\right)$ production is stimulated during

From the Department of Medicine, Winthrop-University Hospital, Mineola, NY; and the Health Sciences Center, State University of New York at Stony Brook. 
periods of high calcium demand such as growth, ${ }^{(5.6)}$ pregnancy, (7) or low-calcium intake. ${ }^{(4.5,8)}$ This steroid, $1,25-(\mathrm{OH})_{2} \mathrm{D}$, is then rapidly localized in the intestine and enhances absorption of calcium and phosphate.

A negative calcium balance can be found in older rats fed a low-calcium diet. ${ }^{(9)}$ Considerable evidence suggests that there is an age-related decline in the efficiency of intestinal calcium absorption in rats ${ }^{(10)}$ and humans. ${ }^{(11)}$ In addition, there is an age-related decline of renal production of 1,25 $(\mathrm{OH})_{2} \mathrm{D}$ and intestinal calcium absorption efficiency in response to a low-calcium diet. ${ }^{(5.12)}$

We, therefore, hypothesized that caffeine administration to older rats may lead to negative calcium balance because of their inability to compensate for calcium loss. The present study was designed to test this hypothesis by comparing the sequential changes of serum calcium, PTH, 1,25$(\mathrm{OH})_{2} \mathrm{D}$ levels, and intestinal calcium absorption in young and adult rats during chronic administration of caffeine.

\section{MATERIALS AND METHODS}

Male Sprague-Dawley rats, either after weaning ( 4 weeks old) or at 12 to 13 months old, were fed a diet containing $0.5 \%$ calcium and $0.54 \%$ phosphorus (Teklad diet TD 81319). After 1 week of adaptation to the diet, the animals were divided into control and caffeine-treated groups. Caffeine was administered subcutaneously to the rats at a dose of $10 \mathrm{mg} /(0.1 \mathrm{~kg})^{3 / 4}$ metabolic body weight ${ }^{(13)}$ daily during the experimental period. The control group received vehicle subcutaneously each day.

Calcium metabolism was studied by the method of Hurley et al., ${ }^{(14)}$ which combined a kinetic study using ${ }^{45} \mathrm{Ca}$ with a short-term classical balance study. Each study included six rats per group. They were given an intravenous injection containing $20 \mu \mathrm{Ci}$ of ${ }^{45} \mathrm{Ca}$ as $\mathrm{CaCl}_{2}$. A 48-hr urine was collected for the measurement of urinary calcium, radioactivity, and creatinine. Body weight and food intake were recorded daily. Feces were collected during a 48-hr period between 6 and $54 \mathrm{hrs}$ after the injection of ${ }^{45} \mathrm{Ca}$. The feces were marked by administering $0.1 \mathrm{ml}$ of $10 \%$ carmine solution by gavage at the beginning and the end of the 48-hr period. The animals were sacrificed when the balance study was completed and the serum samples were collected for analysis.

Samples of the diet and the feces were ashed in a muffle furnace at $560^{\circ} \mathrm{C}$ for $24 \mathrm{hrs}$, then brought up to volume with $2 \mathrm{~N} \mathrm{HCl}$. Serum, urinary, fecal, and dietary calcium were measured by atomic absorption spectrophotometry (Perkin-Elmer 560). Radioactivity was measured using a liquid scintillation counter (LKB 1210).

Calcium balance was estimated as the difference between the ingested and the urinary + total fecal calcium. The true absorbed calcium and endogenous fecal calcium were measured with the aid of ${ }^{45} \mathrm{Ca} .{ }^{(14)}$ The endogenous fecal $\mathrm{Ca}$ was determined through the relationship $V f=V u \times R f / R u$, where $V f$ is the endogenous fecal $\mathrm{Ca}, V u$ is the urinary $\mathrm{Ca}$, and $R f$ and $R u$ are, respectively, the total radioactivity of the feces and urine in the $48 \mathrm{hrs}$ following the ${ }^{45} \mathrm{Ca}$ injec- tion. True absorbed calcium was measured as the difference between ingested $\mathrm{Ca}+V f$ and the total fecal calcium. The absorption coefficient of $\mathrm{Ca}$ (in percentage) was measured as the ratio (true absorbed $\mathrm{Ca} / \mathrm{Ca}$ ingested) $\times 100$.

Serum vitamin D metabolites were measured by the method of Shepard et al. (15) Immunoreactive PTH concentrations were measured using a double antibody heterologous radioimmunoassay. ${ }^{(16)}$ The antibody against bovine PTH was derived from guinea pigs. The assay is specific toward the carboxy-terminal sequence of parathyroid hormone. Cross reaction with the aminoterminal portion of the peptide is negligible. Human PTH was used as the standard. Accordingly, this standard curve was used to determine rat serum iPTH in human PTH equivalents. ${ }^{(17)}$ Student's $t$-test was employed for the statistical evaluation of the data. ${ }^{(18)}$ Two-way analysis of variance (ANOVA) with repeated observations was used to compute the $F$-ratio where appropriate. ${ }^{(19)}$

\section{RESULTS}

Table 1 shows the effect of chronic administration of caffeine on body weight, food intake, and the metabolism of calcium in the young growing rats. During the 4-week experimental period, the young growing control rats had a linear gain in body weight. The total fecal $\mathrm{Ca}$, endogenous fecal $\mathrm{Ca}$, true $\mathrm{Ca}$ absorption, and net $\mathrm{Ca}$ balance were increased in proportion to the increase in food intake (expressed as $\mathrm{Ca}$ ingested).

In contrast with the control group, food intake and body weight did not increase following 4 days' administration of caffeine. The suppression of food intake and weight gain by caffeine decreased with time. Administration of caffeine resulted in an increase in the excretion of endogenous fecal $\mathrm{Ca}$ and urinary $\mathrm{Ca}$ which was apparent by day 4 and sustained during the 4-week period of the experiment. However, one week's administration of caffeine to the young growing rats had no effect on the intestinal absorption coefficient of calcium. This increase in the excretion of calcium without a change in the absorption of calcium resulted in a decrease in the net balance of calcium after the first week's administration of caffeine. Net calcium balance after one week of caffeine was significantly lower than in the control group.

There was a gradual decrease in the intestinal absorption coefficient of calcium observed in the young growing control rats of from 5 to 9 weeks of age. However, this pattern was not apparent in the caffeine-treated group. The absorption coefficient of calcium of the caffeine-treated rats became higher than the control and reached a significant level $(p<.01)$ when applying the ANOVA test to the 4-week repeated measurement. The increase in the absorption coefficient of calcium after 2 weeks' administration of caffeine compensated for the increase in the excretion and resulted in no decrease in the net balance of calcium.

In contrast to the young growing rats, adult control animals experienced no significant change in body weight, food intake, and fecal and urinary calcium excretion dur- 


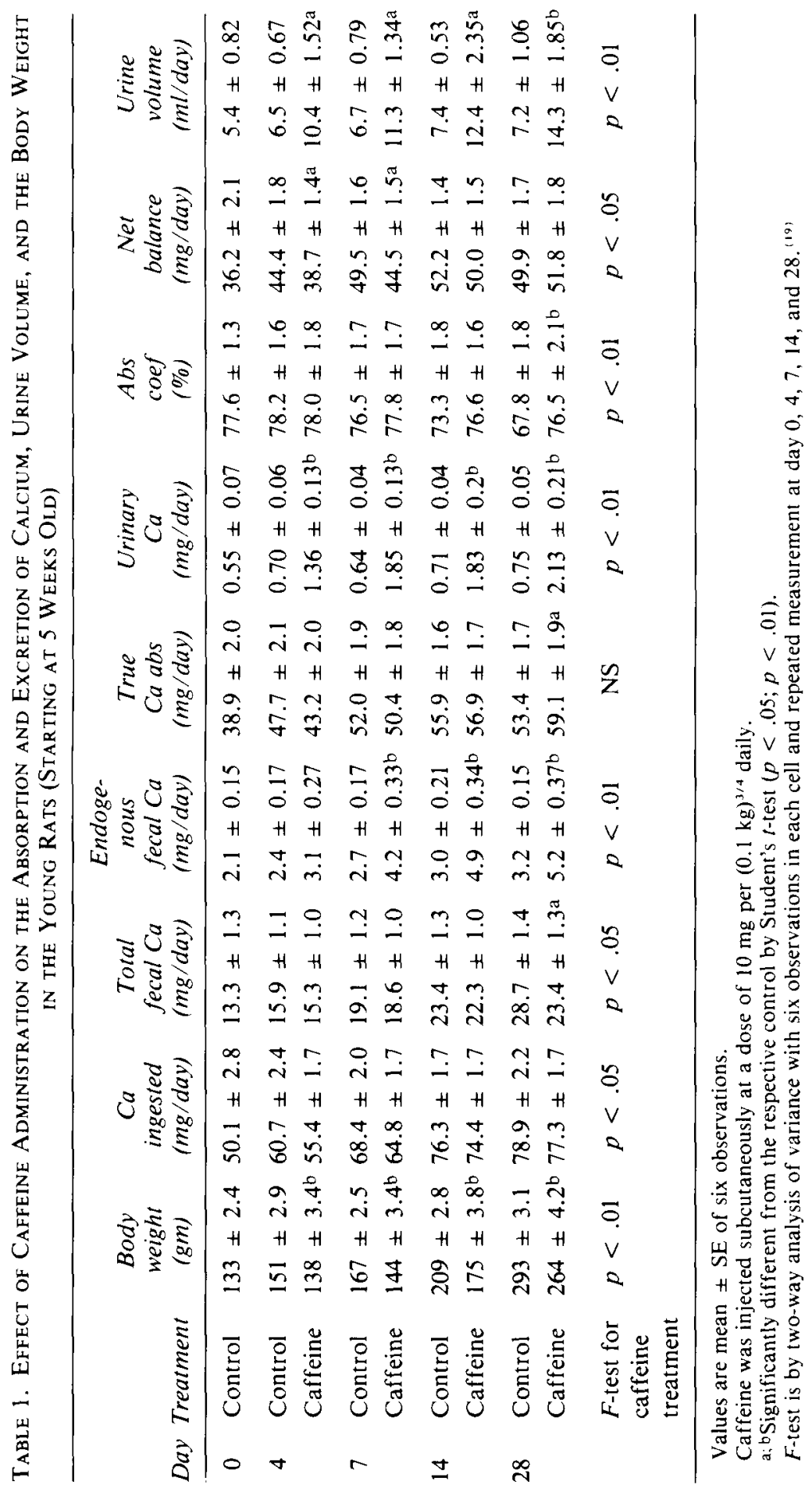




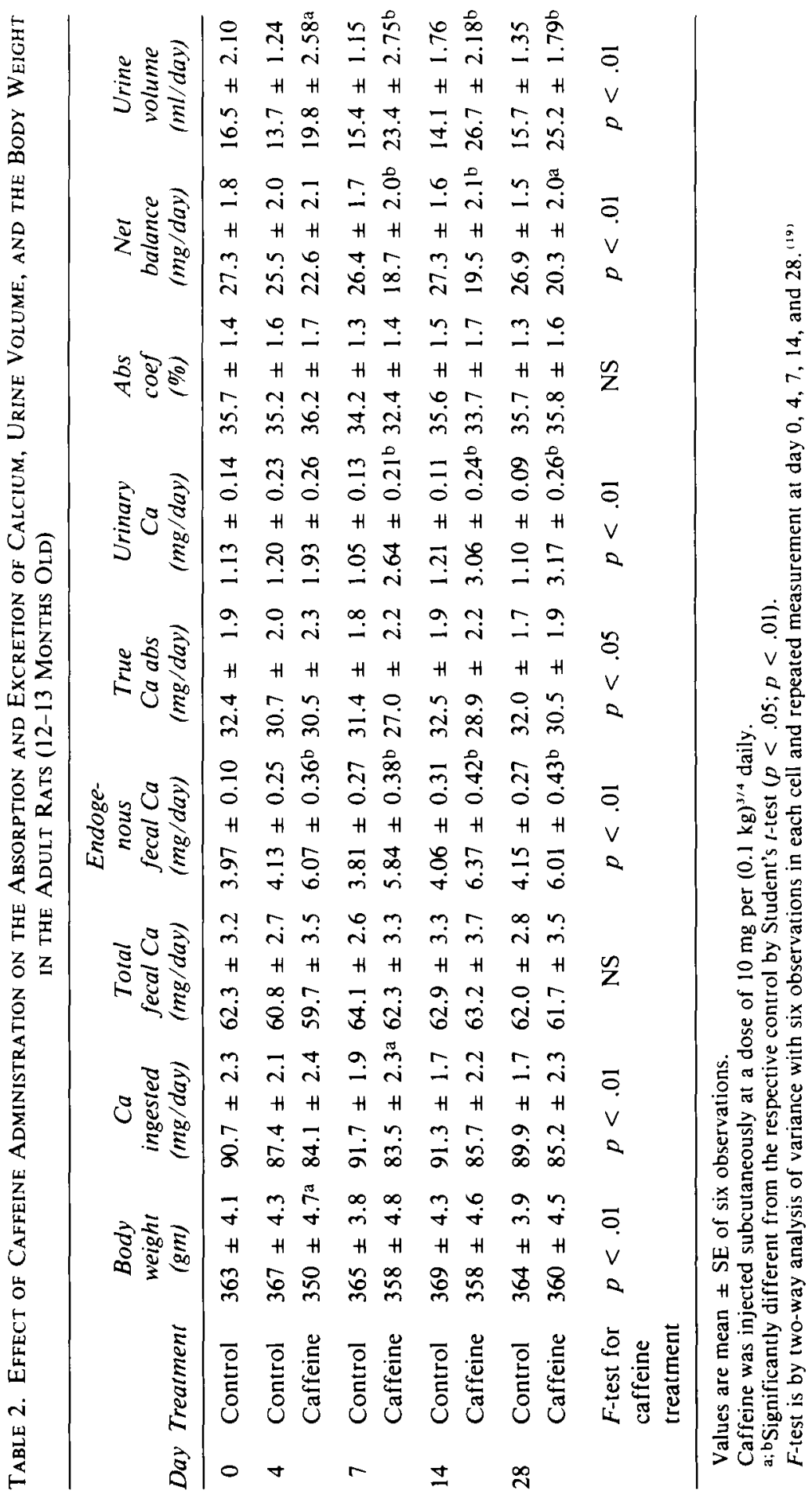


ing the 4-week experimental period. Four to seven days' administration of caffeine to adult rats resulted in a significant decrease in body weight and food intake but an increase in the endogenous fecal and urinary calcium excretion. The suppression of food intake by caffeine was sustained during the 4-week experimental period as was the increase of the excretion of endogenous fecal and urinary calcium excretion. However, the intestinal absorption coefficient of calcium was not changed during the period of caffeine administration. The net balance of calcium was lower in the caffeine-treated group as compared to the control group during the 4-week study.

Serum calcium concentration remained relatively constant in the young growing and adult control rats over the 28-day study period. In contrast, serum calcium concentration in the caffeine-treated young animals exhibited an initial decline to levels significantly lower than control values on day 4 , but then returned toward control levels thereafter (Fig. 1). Serum calcium concentration in the caffeinetreated adult animals was not significantly different from the control levels over the experimental study period.

The basal levels of serum iPTH of the adult rats were higher than in the young rats. Both levels remained relatively constant over the 28-day study period without administration of caffeine (Fig. 2). Administration of caffeine resulted in an increase in serum iPTH in both adult and young rats. This increase became statistically significant by 2 weeks in the caffeine-treated young rats and by 3 weeks in the caffeine-treated adult animals.

In contrast to the serum iPTH, the serum $1,25(\mathrm{OH})_{2} \mathrm{D}$ level in the adult rats was lower than in the young rats and both levels remained constant over the 28 days when caf- feine was not administered (Fig. 3). Administration of caffeine to young growing rats resulted in no effect on the serum levels of $1,25(\mathrm{OH})_{2} \mathrm{D}$ at the first week, followed by a significant increase two weeks later. However, an increase in serum $1,25(\mathrm{OH})_{2} \mathrm{D}$ after caffeine administration was not observed in the adult animals.

\section{DISCUSSION}

The present experiment demonstrates that the effect of caffeine on calcium metabolism differs in young and adult rats. The excretion of endogenous fecal calcium and urinary calcium was higher and the calcium intake (food intake) was lower in both the young and adult rats that received caffeine chronically. However, caffeine increased the intestinal absorption coefficient of calcium only in the young growing group. An initial decrease in serum calcium levels was apparent in the young growing rats, corresponding to the increase in the calcium excretion and the decrease in the intake of calcium after 4 to 7 days of caffeine administration. Serum levels of PTH and $1,25(\mathrm{OH})_{2} \mathrm{D}$ remained unchanged initially, followed by a significant increase 2 weeks after caffeine administration. Thus, it is not surprising that intestinal absorption of calcium was enhanced in caffeine-treated young rats as compared to the agematched control group.

The dosage of the caffeine used in the current rat experiment, $10 \mathrm{mg} /(0.1 \mathrm{~kg})^{3 / 4}$, is equivalent to $1360 \mathrm{mg} /(70 \mathrm{~kg})^{3 / 4}$ in humans when the conversion is based on metabolic body weight. ${ }^{(13)}$ If the average caffeine content in coffee is 85 $\mathrm{mg} / \mathrm{cup}$, this dosage is equivalent to the consumption of 16

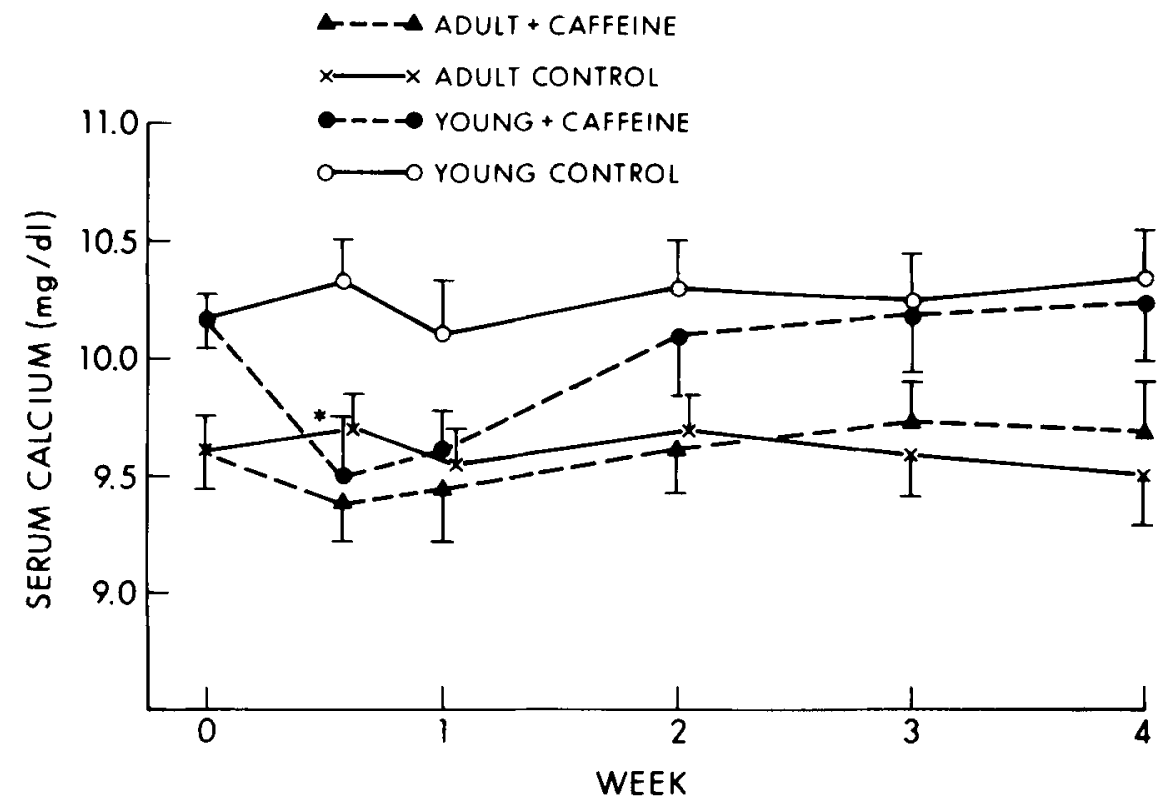

FIG. 1. Effects of caffeine administration on the serum levels of calcium in young and adult rats. Values are mean \pm S.E. of six observations. The daily dosage of caffeine administered was $10 \mathrm{mg}$ per $(0.1 \mathrm{~kg})^{3 / 4}$ body weight. * $=$ significantly different from the young control at day 4 by Student's $t$-test $(p<.05)$. 


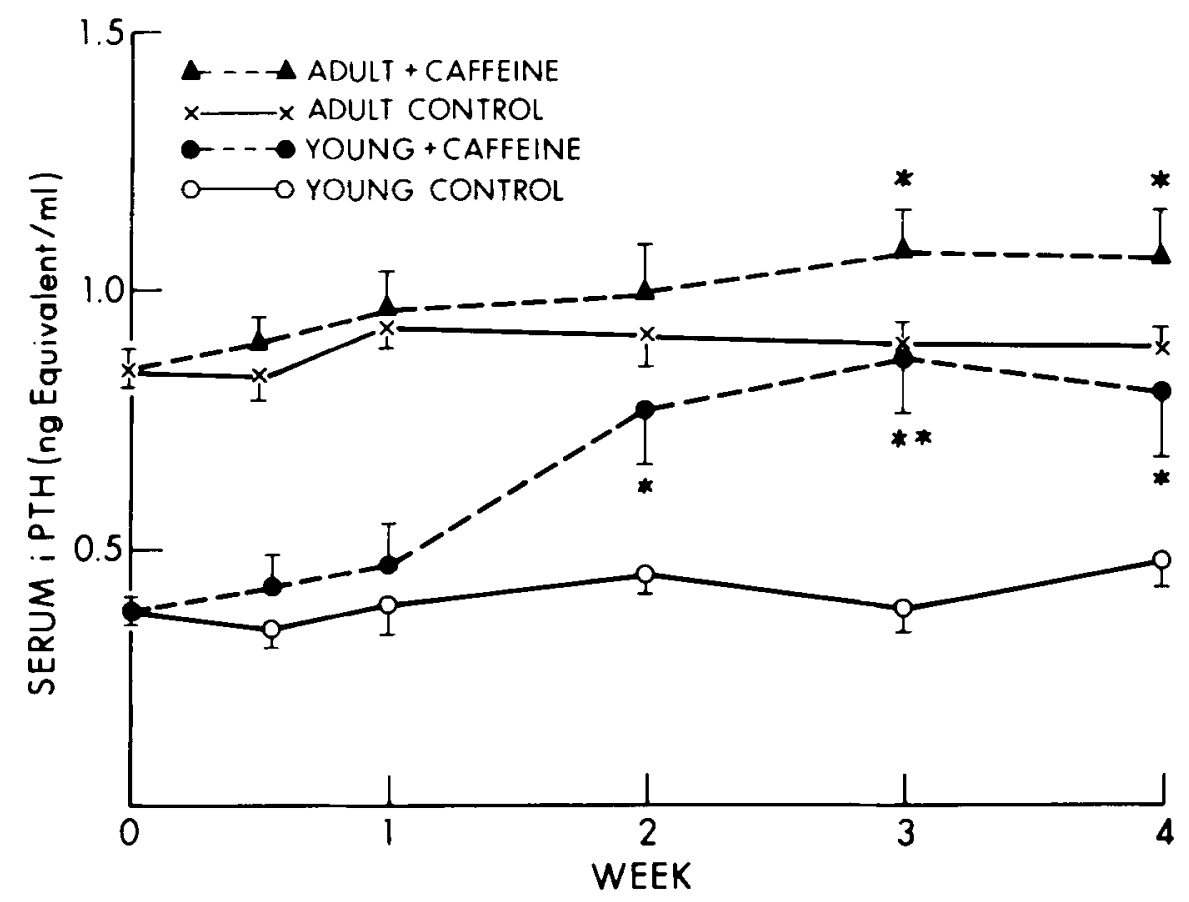

FIG. 2. Effects of caffeine administration of the serum levels of parathyroid hormone (iPTH) in young and adult rats. Values are mean \pm S.E. of six observations. The daily dosage of caffeine administered was $10 \mathrm{mg}$ per $(0.1 \mathrm{~kg})^{3 / 4} \mathrm{body}$ weight. $* ; * *=$ significantly different from the respective control group by Student's $t$-test $(p<.05 ; p<.01)$.

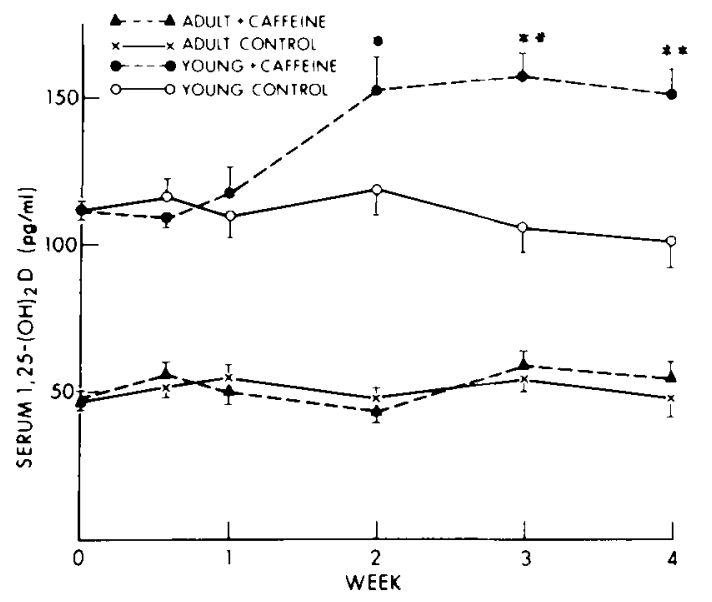

FIG. 3. Effects of caffeine administration on the serum levels of $1,25(\mathrm{OH})_{2} \mathrm{D}$ in young and adult rats. Values are mean \pm S.E. of six observations. The daily dosage of caffeine administered was $10 \mathrm{mg}$ per $(0.1 \mathrm{~kg})^{3 / 4}$ body weight. $* ; * *=$ significantly different from the respective control group by Student's $t$-test $(p<.05 ; p<.01)$.

cups of coffee each day. This amount of caffeine is high for regular consumption in the human diet. Therefore, the relevance of these data for humans has to be tempered.

It has been reported that there is no effect on food intake after caffeine administration. ${ }^{(3,20)}$ The current data show no significant difference in food intake between the caffeine-treated and the age-matched control using Student's t-test. However, the results of repeated observations over
4 weeks indicate a significant difference when ANOVA is applied. Caffeine administration resulted in a mild but persistent suppression of food intake.

Enhanced excretion of calcium could result in transient hypocalcemia, stimulation of $\mathrm{PTH}$ production, and an increase in levels of $1,25(\mathrm{OH})_{2} \mathrm{D}_{3}$. On the other hand, decreased calcium intake could also result in a stimulation of production of $1,25(\mathrm{OH})_{2} \mathrm{D}$. Both mechanisms may be responsible for the increase in the efficiency of intestinal calcium absorption.

Evidently, the increase in serum $1,25(\mathrm{OH})_{2} \mathrm{D}$ in the current study was due to the enhancement of renal conversion of $25(\mathrm{OH}) \mathrm{D}$ to $1,25(\mathrm{OH})_{2} \mathrm{D}$ since a concomitant increase in serum PTH was observed. This stimulation of $1,25\left(\mathrm{OH}_{2} \mathrm{D}\right.$ synthesis is believed to occur because of the increased losses of calcium resulting from caffeine administration. An effect of caffeine administration on the degradation of 1,25 $(\mathrm{OH})_{2} \mathrm{D}$ in young rats has not yet been investigated and therefore cannot be excluded.

An inhibitory effect of caffeine on the conversion of $25(\mathrm{OH}) \mathrm{D}$ to $1,25(\mathrm{OH})_{2} \mathrm{D}$ has recently been reported in isolated renal tubules from vitamin D-deficient chicks. (21) Caffeine inhibits intracellular calcium concentration which suppresses $25(\mathrm{OH}) \mathrm{D}-1 \alpha$-hydroxylase activity in mitochondria. Nevertheless, under in vivo conditions we observed an increase in serum $1,25(\mathrm{OH})_{2} \mathrm{D}$ levels in young rats after chronic administration of caffeine.

A gradual decrease in the intestinal absorption coefficient of calcium was observed in the young growing rat during the 5-9-week-old period without caffeine administration (Table 1). This result is consistent with previous evi- 
dence claiming that rats over 6 weeks old show a decrease in calcium transported by the saturable component, whereas a constant proportion of the ingested calcium is transported by the nonsaturable component. ${ }^{(22.23)}$

Irrespective of the increase in calcium excretion and serum levels of $\mathrm{iPTH}$ and the decrease in food intake after caffeine administration, the serum $1,25(\mathrm{OH})_{2} \mathrm{D}$ levels and intestinal absorption coefficient of calcium in the adult rats remained unchanged. intestinal calcium transport and renal production of $1,25(\mathrm{OH})_{2} \mathrm{D}$ decrease with age. ${ }^{(5,10,12)} \mathrm{We}$ believe that the failure to observe an increase of serum 1,25$(\mathrm{OH})_{2} \mathrm{D}$ after caffeine administration in the adult rat was due to the age-related decline in renal production of $25(\mathrm{OH}) \mathrm{D}-1 \alpha$-hydroxylase. On the other hand, the data in Fig. 2 suggest that the response of serum PTH to the administration of caffeine was lower in the adult rats than in the young rats. Perhaps the increase in PTH in adult rats was insufficient to cause increased renal production of $1,25(\mathrm{OH})_{2} \mathrm{D}$. Moreover, the biological activity of the circulating forms of immunoreactive PTH in young versus old rats is not known. The decrease in the net balance of calcium in the caffeine-treated adult rats is apparently due to both the age-related decline in the renal production of 1,25 $(\mathrm{OH})_{2} \mathrm{D}$ and the impaired ability to increase intestinal calcium absorption in response to the loss of calcium.

The observed increase in the excretion of calcium after caffeine administration confirms previous reports in human and animal studies. ${ }^{(1.3)}$ This increase in the excretion of calcium was also apparent in both young and adult animals. In addition, adult rats showed a decline in renal production of $1,25(\mathrm{OH})_{2} \mathrm{D}$ and in intestinal absorption of calcium. All these factors contributed to the observed decrease in the net calcium balance in the caffeine-treated adult rat.

The inability to synthesize sufficient amounts of 1,25$(\mathrm{OH})_{2} \mathrm{D}$ to meet the needs for calcium balance is a primary event in the aging process. ${ }^{(5.11 .24)}$ Many older people consume diets which are deficient in calcium. ${ }^{(25-27)}$ Enhancement of calcium excretion in urine and feces after the consumption by the elderly of beverages containing caffeine could accelerate the problem of negative balance of calcium. The present study in an animal model supports the suggestion that chronic administration of caffeine to the adult human could lead to a gradual deterioration of calcium balance.

\section{REFERENCES}

1. Heaney RP, Recker RR 1982 Effects of nitrogen, phosphorus, and caffeine on calcium balance in women. $J$ Lab Clin Med 99:46.

2. Daniell HW 1976 Osteoporosis and the slender smoker. Arch Intern Med 136:298.

3. Yeh JK, Aloia JF, Semla HM, Chen SY 1986 Influence of caffeine on the metabolism of calcium and retention and excretion of sodium, potassium, phosphorus, magnesium, zinc and copper in rals. J Nutr 116:273.
4. Garabedian M, Holick MF, DeLuca HF, Boyle IT 1972 Control of 25-hydroxycholecalciferol metabolism by parathyroid glands. Proc Natl Acad Sci USA 69:1673.

5. Armbrecht HJ, Forte LR, Halloran BP 1984 Effect of age and dietary calcium on renal $25(\mathrm{OH}) \mathrm{D}$ metabolism, serum 1,25(OH) ${ }_{2}$ D and PTH. Am J Physiol 246:E266-270.

6. Chesney RW, Rosen JF, Hamstra AJ, DeLuca HF $1980 \mathrm{Se}-$ rum 1,25-dihydroxyvitamin $D$ levels in normal children and in vitamin D disorders. Am J Dis Child 134:135.

7. Boass A, Toverud SU, McCain TA, Pike JW, Haussler MR 1977 Elevated serum level of 1-alpha,25-dihydroxycholecalciferol in lactating rats. Nature 267:630.

8. Ribovich ML, DeLuca HF 1975 The influence of dietary calcium and phosphorus on intestinal calcium transport in rats given vitamin D metabolites. Arch Biochem Biophys 170:529.

9. Armbrecht HJ, Gross CJ, Zenser TV 1981 Effect of dietary calcium and phosphorus restriction on calcium and phosphorus balance in young and old rats. Arch Biochem Biophys 210:179.

10. Horst RL, DeLuca HF, Jorgensen NA 1978 The effect of age on calcium absorption and accumulation of 1,25-dihydroxyvitamin $D_{3}$ in intestinal mucosa of rats. Metab Bone Dis Rel Res 1:29.

11. Gallagher JC, Riggs BL, Eisman J, Hamstra A, Arnaud SB, DeLuca HF 1979 Intestinal calcium absorption and serum vitamin D metabolites in normal subjects and osteoporotic patients: effect of age and dietary calcium. J Clin Invest 64: 729.

12. Armbrecht HJ, Zenser TV, Bruns MEH, Davis BB 1979 Effect of age on intestinal calcium absorption and adaptation to dietary calcium. Am J Physiol 236:E769.

13. Kleiber M 1961 Body size and metabolic rate. In: The fire of life: An introduction to animal energetics. Wiley, New York, pp 177-216.

14. Hurley LS, Gowan J, Milhaud G 1969 Calcium metabolism in manganese-deficient and zinc-deficient rats. Proc Soc Exptl Biol Med 130:856.

15. Shepard RM, Horst RL, Hamstra AJ, DeLuca HF 1979 Determination of vitamin $D$ and its metabolites in plasma from normal and anephric man. Biochem $J$ 182:55.

16. Savjani G 1982 Development of a radioimmunoassay for parathyroid hormone (PTH). Clin Chem 28:1624.

17. Tenner TE, Buddingh F, Yang ML, Pang PKT, Patel D, Savjani $G 1985$ The relationship between serum ionized calcium, parathyroid hormone and development of hypertension in the rat. Clin Chem 31:1013.

18. Winer BJ 1971 Inference with respect to means and variances. In: Statistical Principles in Experimental Design. Second Ed. McGraw-Hill, New York, pp 4-57.

19. Winer BJ $1971 \mathrm{PXQ}$ factorial experiment having an observation per cell. In: Statistical Principles in Experimental Design. Second Ed. McGraw-Hill, New York, pp 431-444.

20. Mohr U, Althoff J, Ketkar MB, Conradt P, Morgareidge $K$ 1984 The influence of caffeine on tumor incidence in Sprague-Dawley rats. Food Chem Toxicol 22:377.

21. Taft JL, French M, Danks JA, Larkins RG 1984 Opposing actions of methylxanthines and dibutyryl cyclic AMP on

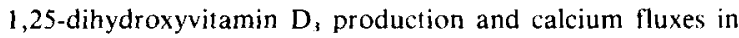
isolated chick renal tubules. Biochem Biophys Res Com 121: 355.

22. Bruns MEH, Bruns DE, Avioli LV 1979 Vitamin D-dependent calcium-binding protein on rat intestine: changes during postnatal development and sensitivity to 1,25-dihydroxycholecalciferol. Endocrinol 105:934.

23. Pansu D, Bellaton C, Bronner F 1983 Developmental changes 
in the mechanisms of duodenal calcium transport in the rat. Am J Physiol 244:G20.

24. Fujisawa $\mathrm{Y}$, Kida K, Matsuda $\mathrm{H} 1984$ Role of change in vitamin D metabolism with age in calcium and phosphorus metabolism in normal human subjects. J Clin Endocrinol Metab 59:719.

25. Odland LM, Mason RL, Alexeff AI 1972 Bone density and dietary findings of 49 Tennessee subjects. II. Dietary considcrations. Am J Clin Nutr 25:908.

26. Jowsey J 1978 Why is mineral nutrition important in osteoporosis? Geriatrics 33:39.

27. Heaney RP, Gallagher JC, Johnston CC, Neer R, Parfitt
AM, Whedon GD 1982 Calcium nutrition and bone health in the elderly. Am J Clin Nutr 36:986.

Address reprint requests to: James K. Yeh, Ph.D. Department of Medicine Winthrop-University Hospital 259 First Street Mineola, NY 11554

Received for publication October 7, 1985; in revised form December 16, 1985; accepted January 13, 1986. 